Article

\title{
Non-Invasive Identification of Vulnerability Elements in Existing Buildings and Their Visualization in the BIM Model for Better Project Management: The Case Study of Cuccagna Farmhouse
}

\author{
Elsa Garavaglia ${ }^{1, *(D)}$, Anna Anzani ${ }^{2}$, Fabio Maroldi ${ }^{1}$ and Fabio Vanerio ${ }^{1}$ \\ 1 Department of Civil and Environmental Engineering, Politecnico di Milano, 20133 Milano, Italy; \\ fabio.maroldi@polimi.it (F.M.); fabio.vanerio@polimi.it (F.V.) \\ 2 Department of Design, Politecnico di Milano, 20158 Milano, Italy; anna.anzani@polimi.it \\ * Correspondence: elsa.garavaglia@polimi.it
}

Received: 21 February 2020; Accepted: 15 March 2020; Published: 20 March 2020

Featured Application: The procedure could be applied, on a municipal or territorial scale, in order to proceed with a rapid assessment of the vulnerability of the existing historical heritage.

\begin{abstract}
Due to the conjunction between the European and African plates, complex tectonic phenomena take place in the Mediterranean basin. These phenomena cause more or less violent seismic resentments in the countries facing the basin itself. The diffused built historical heritage, characteristic of villages in the Mediterranean countries, is the most vulnerable toward seismic action, and in case of a catastrophic event can cause the loss of human lives. In Italy, the protection of historic buildings is a significant issue, and many regions promoted policies to ensure the safety of the diffused built heritage. Research groups work in synergy to develop procedures for the vulnerability assessment of existing buildings and to define appropriate action plans. This research presents a little or not at all invasive procedure for investigating vulnerability. This procedure is easily replicable and able to support techniques already in use with innovative aspects such as laser scanning of the entire complex and visual identification of vulnerable elements through the BIM (building information modeling) methodology. The procedure applicability is shown in the study of a Milanese farmhouse that has been financed by Fondazione CARIPLO, Bandi 2017 Arte e Cultura-Beni culturali a rischio, Project PRE.CU.R.S.OR.
\end{abstract}

Keywords: existing buildings; seismic vulnerability assessment; non-invasive experimental technics; BIM models

\section{Introduction}

The Mediterranean basin, a cradle of many civilizations and a repository of a remarkable built heritage, is located at the junction between the European and African tectonic plates. This conjunction constitutes the so-called Faglia Giulia that runs along the entire Italian Apennine ridge (INGV Database of individual seismogenetic sources DISS_v3, http://diss.rm.ingv.it/diss/), a set of more or less long faults, often almost parallel to each other and juxtaposed, sometimes transversal, whose movements are the cause of seismic resentments in the peninsula. In recent years, the land movements recorded on the Italian Apennine ridge have caused considerable losses in the historical heritage of the affected regions, not to mention the consequent loss of human lives due to the induced collapses. The reason for these disasters is linked to the high vulnerability that characterizes the Italian historical heritage, as 
well as the historical heritage of all countries in the Mediterranean basin, which is not exempt from vulnerability to seismic actions.

A campaign to secure the diffused built heritage requires a careful assessment of the buildings' vulnerability and an economic commitment on the part of their owners. Since 2014, the ReLUIS Network of Seismic Engineering University Laboratories (http://www.reluis.it/) has been working to survey the existing heritage and achieve a reliable vulnerability classification. With the creation of the Casa Italia department (http://www.casaitalia.governo.it/it/) in 2016, a campaign was launched to raise public and administrative awareness of the need to secure public and private buildings, also encouraged by the introduction of possible tax benefits.

In recent years, to support and integrate government initiatives, seismic research has developed numerous investigation methods aimed at the census of aggregate buildings and the subsequent identification of minimum units and structural units on which base the seismic behavior can be analyzed.

In complex urban situations, such as those present in historical centers, this census is not easy. In recent decades, numerous studies have adopted Earth geo-referencing (GIS) technology. Such tool allows association of an object not only to a geo-referenced location that is easy to browse, but also to some of its peculiar characteristics. In the seismic field, this methodology has made it possible to associate each geo-referenced object with the evaluated level of vulnerability. Consequently, vulnerability maps of public and private buildings of entire municipalities could be drawn up [1-12].

To achieve both more detailed investigations on buildings seismic behavior and 3D representation of the level of vulnerability characterizing some construction elements, recent research focuses on the use of Building Information Modeling (BIM).

The BIM methodology is used in the identification phase of vulnerable structural elements; as a possible self-diagnosis process in the pre- and post-earthquake phase if associated with a health monitoring system; as a tool for the creation of an emergency hub to control and shutdown particular facilities (e.g., gas pipes) in the event of an earthquake [13].

As for the use of BIM in the field of seismic vulnerability, the structural analysis, seismic response assessment, and fragility curves associated with different levels of damage are implemented in a BIM environment in order to obtain a 3D graphical display of vulnerable or damaged elements as well as their associated level of vulnerability or damage. A cost analysis also allows the development of clearer intervention strategies for both the designers and the clients [13-16].

The latter also includes the research proposal presented in this paper. The investigation procedure, replicable on different buildings, is based on a quick assessment of the vulnerability obtained with:

- The application of reliable methodologies already known in the literature,

- The use of laser scanner surveys,

- The implementation of the results in a BIM environment.

The implementation of the results in a BIM environment aims to obtain an effective graphical representation of the different aspects of building vulnerability, their severity and possible co-presence, thanks to the opportunity offered by the BIM methodology to perform queries on probable occurrence scenarios (in this case vulnerability scenarios), including the level of vulnerability found on each interrogated element. This methodology is a first approach to the graphical representation of historical buildings vulnerability. It can already be useful for planning a possible targeted diagnostic campaign and for designing suitable interventions of seismic adaptation or improvement addressed to solve the problems that have emerged. The implementation of the economic evaluation of the diagnostic and seismic improvement interventions associated with every possible investigation scenario will be the future objective of this research.

The proposed procedure has been applied to safeguard Cascina Cuccagna, a historic farmhouse in the urban fabric of Milan city. The safety works have been partially financed by Fondazione Cariplo in the framework of the calls for proposals Art and Culture-Cultural Heritage at risk. 
The paper is made of three sections: the first section presents the investigation procedure for the vulnerability assessment of historic buildings. The second section introduces Building Information Modeling (BIM) as a method of graphic detection of building vulnerabilities and of their impact on the buildings' overall ability to withstand an earthquake of a certain magnitude. The third section presents an application of the proposed method to Cascina Cuccagna, a historic building located in the city of Milan, Italy.

\section{The Procedure}

The knowledge of a building and of its history is an essential prerequisite for any safeguarding action; therefore, all possible historical documentation summarizing the different construction phases of the building should be retrieved and, if possible, their typical construction techniques.

Another form of knowledge comes from a detailed survey of the building in its current state, to be compared with a previous survey, if available.

The next phase of knowledge will require visual and photographic investigations of the building and the outline of its possible crack pattern. The identification of the loads acting on the structural elements will also be important, as well as the evaluation of the mechanical qualities of the masonry, wooden elements, and floors.

The results of this first phase of investigation provide enough elements to face an initial and rapid assessment of possible vulnerabilities.

\subsection{Historical Survey of the Building}

In order for an intervention to be structurally effective, compatible with the existing built patrimony, and respectful of its material, constructive and documentary characters, an articulated and interdisciplinary survey has to be carried out. A fundamental contribution to the study of an existing building or a constructed centre is the historical survey, which should take account of indirect and direct sources of information.

Analysis of indirect sources include cataloguing of the data collected through documentaries, archives, and bibliographic information, with the aim to reconstruct the evolution of the complex, its building, and transformation phases and its load history as an history of the earthquakes that occurred in the past. When known, the seismic history of the building is particularly relevant with respect to the safety and intervention aspects. Of great relevance are also the iconographic elements (views, ancient documents) giving information on the historical housing, allowing the evaluation of the transformations of a territory and the comparison with its present configuration.

A compared study is fundamental, especially when the research objects are minor centers or rural architectures. If the documental (indirect) sources do not allow a complete reconstruction of the complex evolution, the historical information coming from the documents should be verified in situ and accompanied by a direct analysis of the buildings. Direct sources, which sometimes are the sole available if historic documents have been lost, come from the observation of the building itself as a data source and include various methods for approaching the knowledge of the building and its chronological phases. They can take advantage from a multidisciplinary approach which critically combines the information coming from the detection of the adopted constructive techniques and materials, traces of previous interventions, epigraphic and heraldic documentations if present, decorative apparatus, and a stratigraphic survey when possible.

\subsection{Geometry and Material Knowledge: Help Comes from the Laser Scanner Survey}

In the vulnerability assessment, the laser scanner is certainly a useful type of survey. This methodology is able to provide a 3D survey of the entire building, its precision depending on the finesse of the instrument and the density of the measured points. The output is a point cloud that represents an operational guide for computer aided design (CAD) and BIM graphic rendering programs capable 
of transforming it into more classic, very detailed, reproductions such as plans, elevations and sections (Figure 1).

As we will see, the laser scanner survey also allows the construction of a 3D model of the entire building that serves as a basis for the Building Information Modeling (BIM), here used in the identification of vulnerable elements and their associated degree of vulnerability.

The knowledge process of an existing building should necessarily involve the detection of its constructive materials and techniques, aimed at the reduction and control of physical, chemical, and mechanical material decay. As mentioned, graphic representation is a fundamental tool in the preliminary phase of knowledge as well as an accurate survey of the building in all its formal, material, and degradation aspects, as well as in the subsequent preservation project.

The material survey is a fundamental tool of inquiry into the building and should be coupled with the historical research and the geometric survey. It should thoroughly study the construction consistency, the material origin and the production technique, the opening features which can help dating the construction phases, and should note its features and peculiarities such as alignments, wall thickness diversities, discontinuities, and variations of the wall apparatus, which are always indicative of some significant historical-artistic or simply of technical-constructive choice.

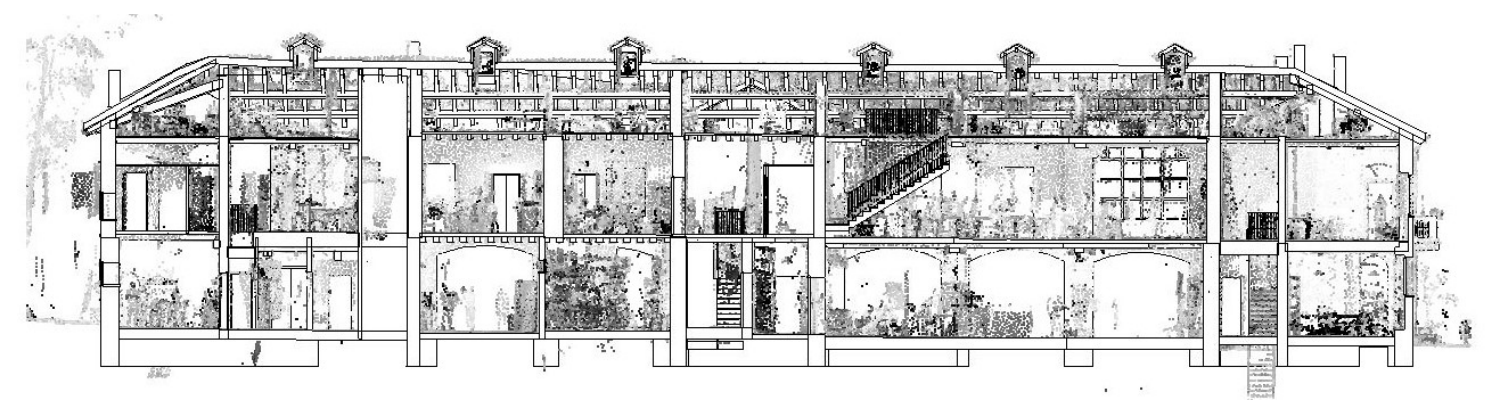

(a)

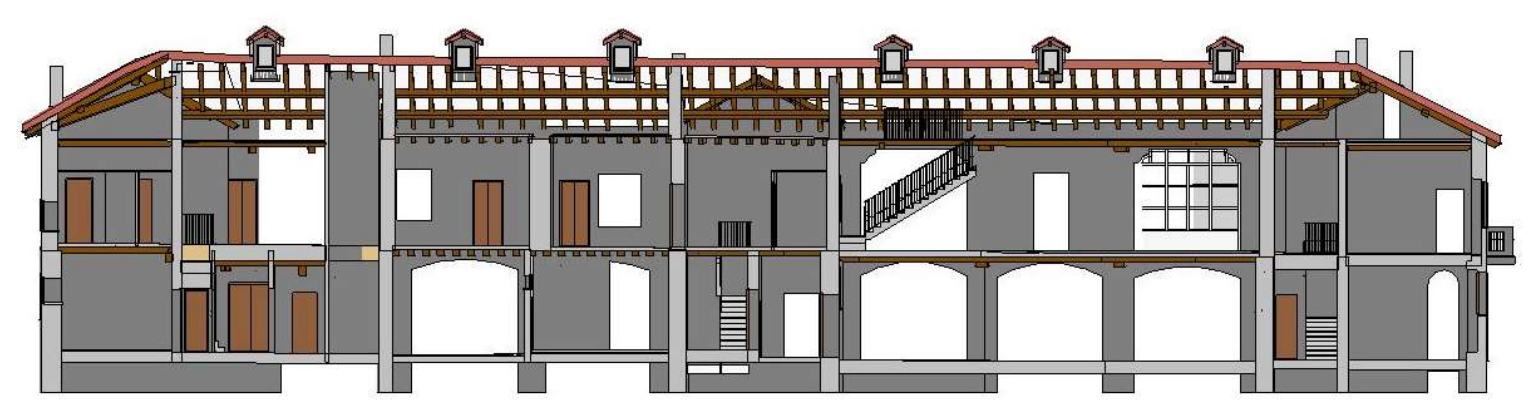

(b)

Figure 1. CAD (Computer-Aided Design) geometric survey obtained from a points cloud: (a) cloud resolution; (b) CAD re-drawing of the transversal section.

\subsection{Redrawing the Crack and Deformation Pattern}

The building assessment requires the architectural redrawing of the complex starting from a traditional survey or from the points cloud obtained from the laser scanner instrumental survey. This redrawing could highlight:

- Possible deformation anomalies in the horizontal elements, symptom of high stress, decrease in load-bearing capacity, constraints failure, etc.; 
- Possible out of plane of vertical elements, symptom of not contrasted horizontal thrusts, lack of interlocking between walls, local instability of unconnected walls, etc.;

- Presence of not contrasted thrusts in the roof or incidence of vaults on load-bearing walls;

- Misalignments between walls and between inter-stories.

These anomalies could threaten the building safety and require a visual check and a more accurate photographic survey.

For all the different parts of the building, the survey should include drawings of the crack patterns, a necessary step to formulate hypotheses on its possible causes and to suggest possible diagnostic investigations to be carried out for a more thorough verification of the problems found.

In the case of a historical asset, a material and pathological survey should also be carried out in order to plan preservation interventions compatible with the historicity of the building.

\subsection{Mechanical Characteristics of Structural Elements and Loads Analysis}

Certainly, the knowledge level reached with rapid investigations and non-destructive tests can only be limited, but it already provides the professional with information on where and how to obtain more precise knowledge levels.

The loads analysis should be carried out taking into account the actions to which the structure is currently subjected, considering any change in its intended use and the replacement of structural elements, floors, roofing membranes, or other transformations undergone by the building during its service life.

If a detailed examination of the flooring system is not possible, the acting loads can be estimated according to the constructive typologies used at the building time or due to whatever change has occurred.

For better knowledge of the mechanical characteristics of the structural elements, more or less invasive experimental tests both in the laboratory and on site will be necessary. The connection between floors and walls, and between walls perpendicular to each other should be investigated on-site. However, the damage level of wooden elements can already be detected through a visual investigation of their crack and deformation patterns, of the constraints quality (if detectable), and of any rottenness, biological, and/or parasitic attack. This could be part of the qualitative vulnerability evaluation and provide useful indications for a selective and targeted diagnosis.

The masonry mechanical qualities will also have to be evaluated experimentally, but reasonable hypotheses on the type of masonry texture present in the building can help to establish its quality and behavior toward in plane and out of plane actions. The historical investigation, associated with the knowledge of the construction techniques typical of the area, will allow achievement of truthful assumptions about the type of masonry, while a possible geo-radar investigation could help understand if the masonry is made of a single or multiple leaves.

A rapid method of characterizing the masonry quality has been developed by Borri et al. [17-20]. Having at their disposal a rich catalogue of masonry typologies typical of Italian regions [21,22] (https://www.abacomurature.it/), the authors have developed a methodology that, on the basis of a sample visual survey of the masonry surface, can provide an index of masonry quality. This classifies masonry into three categories against its possible response to vertical or horizontal-in plane or out of plane-forces: good (A), medium (B), very bad (C) (Table 1 and Figure 2).

The masonry quality index (IQM) calculation is based on the rules of good building. It takes into account the units' quality (type of brick/stone and its geometry), the mortar quality, the presence of staggered joints, in prospect and section (if visible), and the presence of headers or other forms of connection of the wall leaves. Depending on their recorded quality, each of these parameters is assigned a weight. This weight is established on an empirical basis (expert judgment) and on a statistical basis where possible (Figure 2).

The final evaluation associates the masonry with a certain IQM value as shown in Table 1. 
Table 1. Attribution of masonry category.

\begin{tabular}{cccc}
\hline Actions on the Masonry & Class A & Class B & Class C \\
\hline Vertical & $5 \leq \mathrm{IQ} \leq 10$ & $2.5 \leq \mathrm{IQ}<5$ & $0 \leq \mathrm{IQ}<2.5$ \\
Horizontal & $7 \leq \mathrm{IQ} \leq 10$ & $4<\mathrm{IQ}<7$ & $0 \leq \mathrm{IQ} \leq 4$ \\
perpendicular & $5<\mathrm{IQ} \leq 10$ & $3<\mathrm{IQ} \leq 5$ & $0 \leq \mathrm{IQ} \leq 3$ \\
Horizontal coplanar & &
\end{tabular}

\subsection{Initial Vulnerability Assessment}

The redrawing of the building in plan and in elevation allows us to: define the surface of each floor and each inter-storey average height; identify the resistant elements against horizontal actions in two orthogonal directions ( $x$ and $y$ ) and their dimensions in plan (total length and average thickness of the resistant elements in both directions); identify the points of transmission of vertical and horizontal loads (thrusts of vaults and coverage).

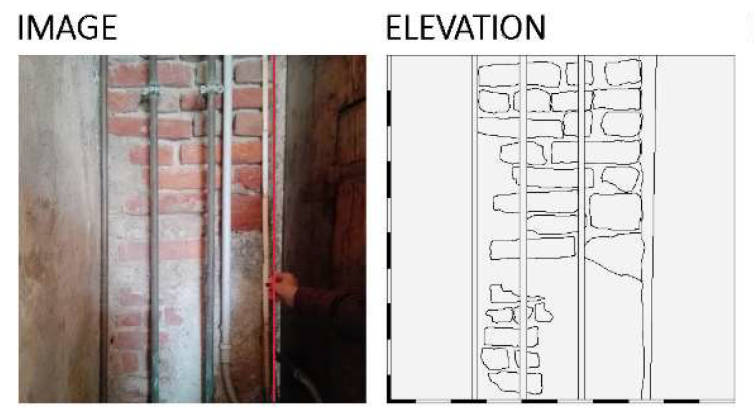

LOCATION
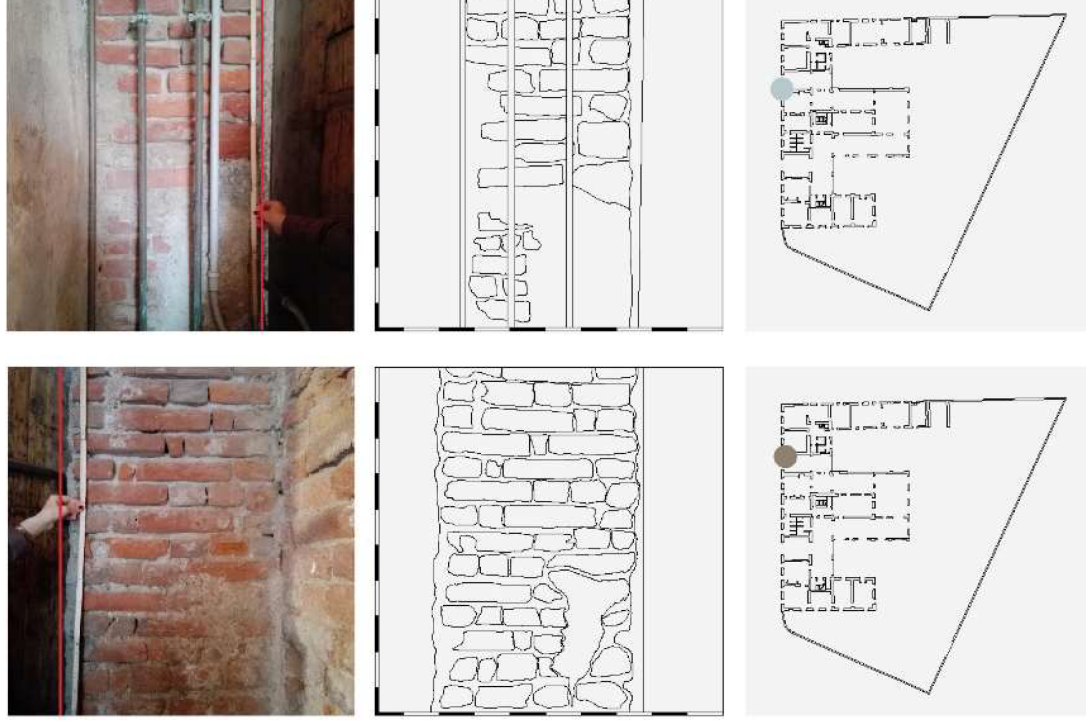
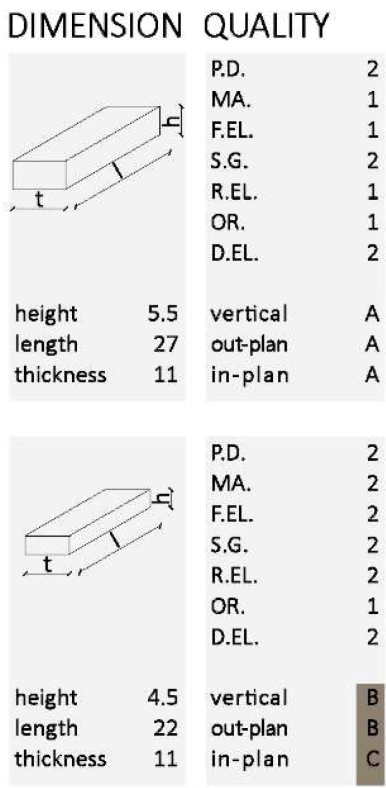

Figure 2. Identification of the masonry quality.

These data are the basis for an initial assessment of the building vulnerability.

Having identified the seismic zone and the parameters that characterize its response spectrum for the reference limit state, Borri et al. $[19,20]$ propose a methodology that allows control of the overall building vulnerability on the basis of:

- An expert judgement on the vulnerability level of the entire building formulated on the basis of the presence, or absence, of 10 possible vulnerability aspects and the severity level found (Table 2).

- Three simplified numerical checks: simplified global check (VG), which allows the definition of the ground acceleration that could lead to collapse; simplified local check (VL), which allows the determination of the acceleration of activation of a given mechanism (overturning, wedge overturning, buckling); simplified static check (VS), which allows the determination of vertical loads only and the safety factor. 
Table 2. C/Q Classification/Quantification) seismic method; structural deficiencies to be considered for vulnerability identification (synthesis) [20].

\begin{tabular}{|c|c|}
\hline $\mathbf{N}$ & Description of Possible Vulnerable Evidences \\
\hline 1 & State of conservation. Extent and severity of significant cracks or serious decay. \\
\hline 2 & $\begin{array}{l}\text { Masonry quality. Assessment of compliance with the rule of art and number of walls with poor } \\
\text { workmanship. }\end{array}$ \\
\hline 3 & Linkage. Connections or metal tying between outer and inner walls and with floors and roofs. \\
\hline 4 & Floors and roofs. Span or insufficient support. \\
\hline 5 & Structural regularity (only on stiff floors). Presence of plane irregularities. \\
\hline 6 & $\begin{array}{l}\text { Inclusion of a building in a block or a line. Corner or head position, presence of protruding or } \\
\text { elevating elements not contrasted by other buildings. }\end{array}$ \\
\hline 7 & Elevation regularity. Mass or stiffness variation between two subsequent levels. \\
\hline 8 & Foundation and soil. Evidence of foundation settlements. \\
\hline 9 & $\begin{array}{l}\text { Local structural defects. Thrusting elements, unsupported walls or pillars, superfetation, } \\
\text { hammering with adjacent buildings. }\end{array}$ \\
\hline 10 & $\begin{array}{l}\text { Vulnerable non-structural elements. Chimneys, parapets, balconies, eaves, veils, badly connected } \\
\text { significantly heavy ceilings. }\end{array}$ \\
\hline
\end{tabular}

The results of the three simplified checks are compared with the safety levels required by the Italian NTC2018 standards for the protection of human life limit state (SLV) for the site under examination, the considered type of building, and the envisaged class of use. These results are expressed in terms of conventional safety factor (SF). In other words: for each of the three checks, $V G, V L, V S$, and for each verified element, there will be a $S F$ factor (e.g., $S F_{V L, x i} S F_{V L, y i}$ factors related to the $V L$ check on element $i$ in the direction $x$ and $y$ ); the minimum safety factor obtained in the check under examination will be divided by the safety factor present in the standard and referred to the SLV state.

$$
S F_{V j}(\%)=\frac{S F_{V j, \text { min }}}{S F_{V j, \text { SLV-Law }}} \text { with } j=\mathrm{G}, \mathrm{L}, \mathrm{S},
$$

$S F_{V j}(\%)$ expressed in percentage, is the conventional safety factor for the check $V j$.

$S F_{V j, \min }$ indicates the minimum safety factor among all the safety factors calculated for the check $V j$ and for all the elements of the structural system, $S F_{V j}, S L V$-Law is the safety factor indicated by the code for the check $V j$.

The minimum among all the safety factors $S F_{V j}$ will determine the vulnerability class of the system [20]

$$
S F(\%)=\min \left\{S F_{V j}(\%)\right\} \quad \text { with } j=\mathrm{G}, \mathrm{L}, \mathrm{S},
$$

The combination of the vulnerability assessments with the minimum safety factor derived from the three simplified numerical checks results into the association of the building with a low, medium, high or very high vulnerability class (Table 3 ).

\begin{tabular}{|c|c|c|c|c|c|}
\hline \multicolumn{5}{|c|}{ Safety Assessment for the State of Life Preservation Limit (SLV) } & $\overline{A+}$ \\
\hline & \multicolumn{5}{|c|}{ Results of the Numerical Assessment } \\
\hline \multirow{2}{*}{$\begin{array}{l}\text { Vulnerability judgment } \\
\text { Low vulnerability }\end{array}$} & $>80 \%$ & $80 \%-60 \%$ & $60 \%-40 \%$ & $40 \%-20 \%$ & $<20 \%$ \\
\hline & A & B1 & B2 & C1 & D1 \\
\hline \multirow{2}{*}{$\begin{array}{l}\text { Medium vulnerability } \\
\text { High vulnerability }\end{array}$} & B1 & B2 & $\mathrm{C} 1$ & $\mathrm{C} 2$ & D2 \\
\hline & B2 & $\mathrm{C} 1$ & $\mathrm{C} 2$ & D1 & D3 \\
\hline Very high vulnerability & $\mathrm{C} 1$ & $\mathrm{C} 2$ & D1 & D2 & $\mathrm{E}$ \\
\hline
\end{tabular}

Table 3. Anti-seismic classification [20]. 
The methodology has been developed within the framework of the POR-ESFR 2007-2013 for the Umbria Region seismic certification/qualification of the existing asset (Seismic C/Q). Currently the guidelines for the seismic C/Q have been formally acquired by the Umbria Region and the Marche Region.

\subsection{Non-Destructive Diagnostics}

For interventions on buildings, the Italian Standard requires more or less severe safety factors depending on the knowledge level reached about the typology and details and mechanical characteristics of the building studied. In order to reduce the severity imposed by the regulatory coefficients, a diagnostic study should be necessary and the investigations previously described can help not to disperse resources, highlighting critical points on which possible experimental tests should focus.

High knowledge levels require in-depth and invasive diagnostic investigations, often not compatible with the available economic resources and the intrinsic value of the asset. Setting up a non-destructive or minimally invasive testing campaign (sonic and ultrasonic tests, superficial and deep penetrometric tests, georadar, partial plaster removal, small inspections, etc.) focused on the areas with the main problems can help contain costs but also reach a higher level of knowledge, as required by regulations.

\subsection{Identification of Vulnerable Elements and the Level of Damage}

In the literature, damage classifications for different types of buildings are available: they are defined from the study of the fragility curves that link the damage probability to the intensity of the seismic event. However, these classifications mainly concern the probable response of a given structural typology to a given seismic action [23-25], not the response of a single vulnerable element in a single building. Therefore, the assessment of the vulnerability level of each element of the building must follow other paths. In 2000 for the Marche Region, Francesco Doglioni proposed to associate the forms of specific vulnerability, often found in existing buildings, with six well-defined causes (Table 4) [26]. This classification can be extended to the entire historical heritage at risk and represents a very important starting point on which the identification of specific vulnerabilities and an initial estimate of the propensity to damage of vulnerable elements for an earthquake of a certain magnitude can be based.

The propensity to damage can be assessed by associating weights to each detected criticality connected with one of the specific vulnerabilities listed in Table 4. These weights can be established according to the detected damage level.

Obviously, this step must be subjected to "expert" judgment. In fact, on the basis of an expert judgment, a certainly subjective, but supported by the results of previous investigations, weight can be assigned to each of the vulnerability forms found and a "judgment" can be formulated on their influence on the overall vulnerable behavior of the building. In this way, each of them will be qualified as absent (0), scarcely influential (1), averagely influential (2), significantly influential (3).

More than one of the specific vulnerabilities listed in Table 4 may be present in the building elements. Now, if each element were affected by more than one form of specific vulnerability, it would be interesting to have an immediate graphical feedback of its vulnerabilities [13-16].

The research presented here focuses on the possibility of using the BIM methodology also in this field, evaluating the effectiveness of a three-dimensional building representation with the graphical identification of elements affected by one or more forms of vulnerability and the classification of their level of influence on the total vulnerability of the building through a given range of colors. 
Table 4. Classification of specific vulnerability forms in thematic groups attributed to six different possible causes.

Thematic Groups of Specific Vulnerability Forms Attributed to:

\begin{tabular}{|c|c|c|c|}
\hline \multirow{6}{*}{1} & \multirow{6}{*}{$\begin{array}{l}\text { Initial methods of } \\
\text { construction }\end{array}$} & $\begin{array}{l}\text { Materials and constructive } \\
\text { techniques }\end{array}$ & $\begin{array}{l}\text { - } \quad \text { Quality of supports and binders } \\
\text { - } \quad \text { Masonry adhesion and/or cohesion }\end{array}$ \\
\hline & & $\begin{array}{l}\text { Geometric and dimensional } \\
\text { masonry characters }\end{array}$ & $\begin{array}{l}\text { - Related to the masonry section: } \\
\text { positioning of the outer leaf } \\
\text { Related to the architectural-structural } \\
\text { elements: slenderness }\end{array}$ \\
\hline & & $\begin{array}{l}\text { Elements that reduce the } \\
\text { masonry cross section }\end{array}$ & $\begin{array}{ll}\text { - } & \text { Presence of fuel pipes } \\
\text { - } & \text { Interruptions due to plants ducts } \\
\text { - } & \text { Eaves/rain pipes within the } \\
\text { masonry section }\end{array}$ \\
\hline & & $\begin{array}{l}\text { Structural elements with } \\
\text { inadequate section }\end{array}$ & $\begin{array}{ll}\text { - } & \text { Slenderness } \\
\text { - } & \text { Poor thickness } \\
\text { - } & \text { Towering elements }\end{array}$ \\
\hline & & $\begin{array}{l}\text { Peculiar openings } \\
\text { distribution }\end{array}$ & $\begin{array}{l}\text { - } \quad \text { Misaligned apertures } \\
\text { - } \quad \text { Apertures close to corners }\end{array}$ \\
\hline & & $\begin{array}{l}\text { Lack of connection between } \\
\text { stone elements }\end{array}$ & $\begin{array}{l}\text { - } \quad \text { Inadequate interlocking } \\
\text { - } \quad \text { Lack of adhesion }\end{array}$ \\
\hline \multirow{5}{*}{2} & \multirow{5}{*}{$\begin{array}{l}\text { Building } \\
\text { transformation } \\
\text { processes }\end{array}$} & Enlargement & \multirow{3}{*}{$\begin{array}{ll}\text { - } & \text { Non-interlocked } \\
\text { - } & \text { Discontinuous } \\
\text { - } & \text { Of heterogeneous material }\end{array}$} \\
\hline & & Super-elevation & \\
\hline & & Closing/opening of apertures & \\
\hline & & $\begin{array}{l}\text { Subtraction of elements or } \\
\text { masonry parts }\end{array}$ & $\begin{array}{l}\text { - } \quad \text { Demolition of partitions } \\
\text { - } \quad \text { Opening of large apertures }\end{array}$ \\
\hline & & $\begin{array}{l}\text { Inadequate or dangerous } \\
\text { structural solutions }\end{array}$ & $\begin{array}{ll}\text { - } & \text { Unsupported walls } \\
\text { - } & \text { Pillars above vaults }\end{array}$ \\
\hline \multirow{4}{*}{3} & \multirow{4}{*}{$\begin{array}{l}\text { Lack of structural } \\
\text { connections and } \\
\text { role of existing } \\
\text { protection } \\
\text { devices }\end{array}$} & Wall-wall connections & - Discontinuities in wall node \\
\hline & & Wall-roof connections & \multirow{2}{*}{$\begin{array}{l}\text { - } \quad \text { Non-compensated local thrust } \\
\text { - } \quad \text { Lack or poor effectiveness of connections }\end{array}$} \\
\hline & & Wall-floor connections & \\
\hline & & $\begin{array}{l}\text { Inadequate or damaged } \\
\text { connection systems }\end{array}$ & $\begin{array}{l}\text { - } \quad \text { Lacking or ineffective ties } \\
\text { - } \quad \text { Inadequate buttresses }\end{array}$ \\
\hline
\end{tabular}


Table 4. Cont.

Thematic Groups of Specific Vulnerability Forms Attributed to:

\begin{tabular}{|c|c|c|c|}
\hline \multirow{4}{*}{4} & \multirow{4}{*}{$\begin{array}{l}\text { Structural } \\
\text { deterioration and } \\
\text { lack of } \\
\text { maintenance }\end{array}$} & Masonry decay & $\begin{array}{l}\text { - } \quad \text { Lack of binder in the joints } \\
\text { - } \quad \text { Masonry de-cohesion } \\
\text { - } \quad \text { Presence of water } \\
\text { - } \quad \text { Decay of stone elements }\end{array}$ \\
\hline & & $\begin{array}{l}\text { Decay of timber elements in } \\
\text { the roofs }\end{array}$ & $\begin{array}{l}\text { - } \quad \text { Heads rotting } \\
\text { - } \quad \text { Decay of secondary elements and/or of } \\
\text { the tables } \\
\text { - } \quad \text { General decay } \\
\text { - } \\
\text { Elements deflection }\end{array}$ \\
\hline & & $\begin{array}{l}\text { Lack of maintenance of } \\
\text { masonry and plasters }\end{array}$ & $\begin{array}{ll}\text { - } & \text { Exposed outer leaf } \\
\text { - } & \text { Plaster efficiency }\end{array}$ \\
\hline & & $\begin{array}{l}\text { Lack of maintenance of the } \\
\text { roof }\end{array}$ & $\begin{array}{l}\text { - } \quad \text { Conditions of the covering layer } \\
\text { - Inefficient eaves and pipes }\end{array}$ \\
\hline \multirow{2}{*}{5} & \multirow{2}{*}{$\begin{array}{l}\text { Previous } \\
\text { structural } \\
\text { damage not } \\
\text { sufficiently } \\
\text { repaired }\end{array}$} & Seismic & $\begin{array}{ll}\text { - } & \text { Cracking } \\
\text { - } & \text { Deformations/out of plumb }\end{array}$ \\
\hline & & Static & $\begin{array}{ll}\text { - } & \text { Cracking } \\
\text { - } & \text { Deformations/out of plumb }\end{array}$ \\
\hline 6 & $\begin{array}{l}\text { Recent structural } \\
\text { refurbishment }\end{array}$ & $\begin{array}{l}\text { Executed with "modern" } \\
\text { techniques }\end{array}$ & $\begin{array}{l}\text { - } \quad \text { Reinforced concrete beams with } \\
\text { inadequate sections and/or detached from } \\
\text { the masonry } \\
\text { - } \quad \text { Non-distributed and } \\
\text { nonhomogeneous injections } \\
\text { - } \quad \begin{array}{l}\text { Reinforced plaster non suitably connected } \\
\text { with the masonry }\end{array}\end{array}$ \\
\hline
\end{tabular}

\section{Building Information Modeling Applied to Seismic Vulnerability}

The 3D design in BIM environment is able to support multidisciplinary collaborative processes useful in the management and control of the building process; in fact, the BIM modeling allows optimization of the planning, implementation, and management of the entire building complex from the architectural, structural, and plant engineering point of view. Each element of the building, created in BIM environment, has parametric characteristics that can be modified: at each project implementation, with additions or changes, the entire design system is updated according to the changes made; this model potentiality allows a flexible management of the entire construction process from design, to building, to maintenance.

BIM modeling can also be used in the interventions on existing assets. In this case, the graphic reproduction of an existing building requires input from a base track; this base can be provided through a points cloud obtained from a laser scanner survey, or a geometric survey file resulting from computer aided design (CAD) programs.

The 3D model, created as a geometric survey of the building, is then parameterized and reproduced as a BIM model. The BIM modeling allows association of to each building element (component) and 
all its characteristics (geometry, material, mechanical parameters, etc.) in parametric form. Taking advantage of this BIM environment peculiarity, it seems interesting to associate to each element, in parametric form, with the vulnerability characteristics resulting from previous investigations.

The first step required by the parameterization procedure is creating an association between the specific vulnerabilities found and their assigned weights for each individual element of the building. The purpose of having a graphical resolution of the vulnerabilities requires that each vulnerability and each weight is associated with a field that identifies the type of specific vulnerability and the weight it could have on the overall vulnerability of the building. The graphical representation offered by the BIM modeling is certainly useful to have an immediate picture of the distribution of some vulnerabilities, and their danger level, throughout the whole building. These graphic representations can be obtained through targeted queries, a classic approach to work in a BIM environment.

These queries can concern the same specific vulnerability but with different weight: $0=$ absent, 1 = light damage, 2 = moderate damage, 3 = severe damage.

- Query01_Querying the same vulnerability:

- "Presence of flue pipes" classified with weight 2.

- " "Presence of flue pipes" classified with weight 3.

In the example shown, query01 gives the position of voids inside both load-bearing and non-load-bearing walls, and the weight associated with this vulnerability according to the recorded damage level.

Or they can concern two different vulnerabilities

- Query02_Querying two vulnerabilities:

- "Uncompensated localized roof thrust" ranked with weight 3;

- "Unconnected building expansion" classified with weight 2.

Query02, thus defined, gives the critical and significant points for the possible detachment or partial overturning of the masonry structure.

Another possible query is for three or more vulnerabilities.

- Query03_Querying three or more vulnerabilities:

- "No or poor effectiveness of wall-roof connection" classified with weight 2.

- "Missing or ineffective tie rods" classified with weight 2.

- "Condition of the roof covering" classified with weight 1.

This type of query, for instance, is useful for understanding the state of connection and degradation of the roof structures with respect to the underlying masonry.

The parametric modeling and the performed queries presented here seem to overcome the difficulties of a synthetic and global reading of the vulnerabilities present in a building. In fact, the classification of vulnerabilities is generally reported on spreadsheets and tables that are not easy or quick to interpret, especially for non-professionals, as the property owners can be. A graphic representation certainly helps the owner to better understand the problems of his building and to take informed decisions on the interventions to be carried out.

\section{Application of the Proposed Procedure to the Case Study of Cuccagna Farmhouse in Milan (North Italy)}

The methodology presented in this work has been applied in a project of redevelopment and anti-seismic safety of a historical asset in the city of Milan, Italy.

In 2017, the pilot project PRE.CU.R.S.OR. was the winner of a grant from the Fondazione Cariplo di Milano in the field of Art and Culture-Cultural Heritage at Risk, a funding line that supports preservation interventions on assets protected by law. The involved asset is Cascina Cuccagna, one 
of the rural buildings still existing in the city of Milan (Figure 3). Until about the middle of the 20th century, farmsteads represented the place of life and productivity for most of the inhabitants of the Lombard plain. Still today, they are a remarkable architectural resource and often, as in the case of Cascina Cuccagna, they are used with different functions from the original ones.

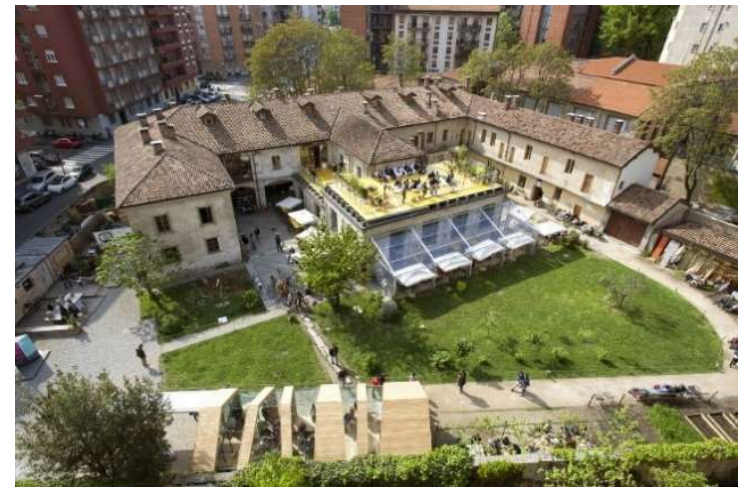

(a)

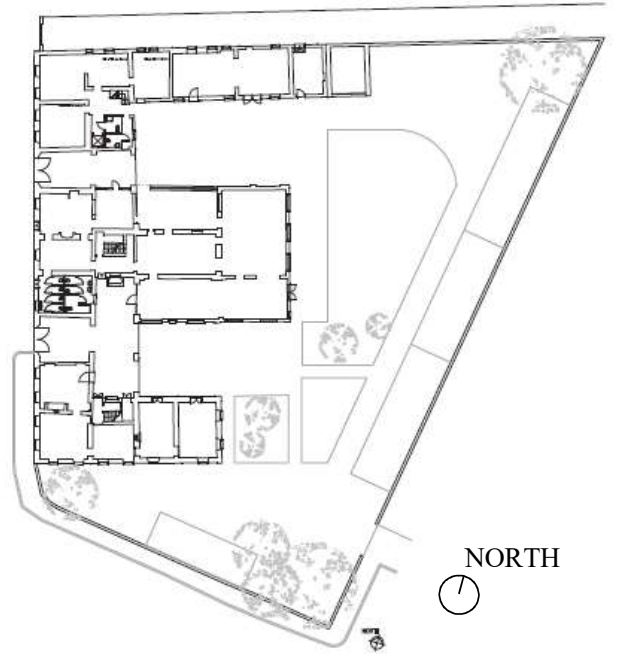

(b)

Figure 3. Cascina Cuccagna, (a) overall view and (b) ground floor plan.

Cascina Cuccagna represents an ideal scenario for a replicable "pilot project" of progressive improvement of the earthquake resistance conditions on historical buildings. In fact, from the construction point of view, its model is highly repetitive in Lombardy and more generally in northern Italy. It is located in a context of medium-low seismicity that allows testing of investigation and intervention techniques in safe conditions. Cascina Cuccagna is also the site of many cultural, social, and economic activities and a good place for the culture dissemination of risk protection through the direct observation of the actions to be taken, their invasiveness and interference with the users' lives, the implementation timing, the possibility of extending them over time, and the related costs.

\subsection{Historical Investigation, Survey, Redrawing, and Crack Pattern}

Based on the historical research, the phases of expansion and modification of the original building over the years could be reconstructed (Figure 4).

The contact surfaces between portions built in different periods are delicate and require attention because, often, the extensions are made without sufficient connection to adjacent constructions. Some of these surfaces have also been highlighted by redrawing the crack pattern (Figure 5): the red cracks in Figure 5 are an example of this. The crack pattern survey performed room by room (Figure 6) has highlighted other criticalities where a more in-depth investigation is required. Instead, the building redrawing in a BIM environment from the laser scanner survey points cloud has highlighted some shortcomings at the deformation level: floor sags and possible lack of plomb (Figure 7). 


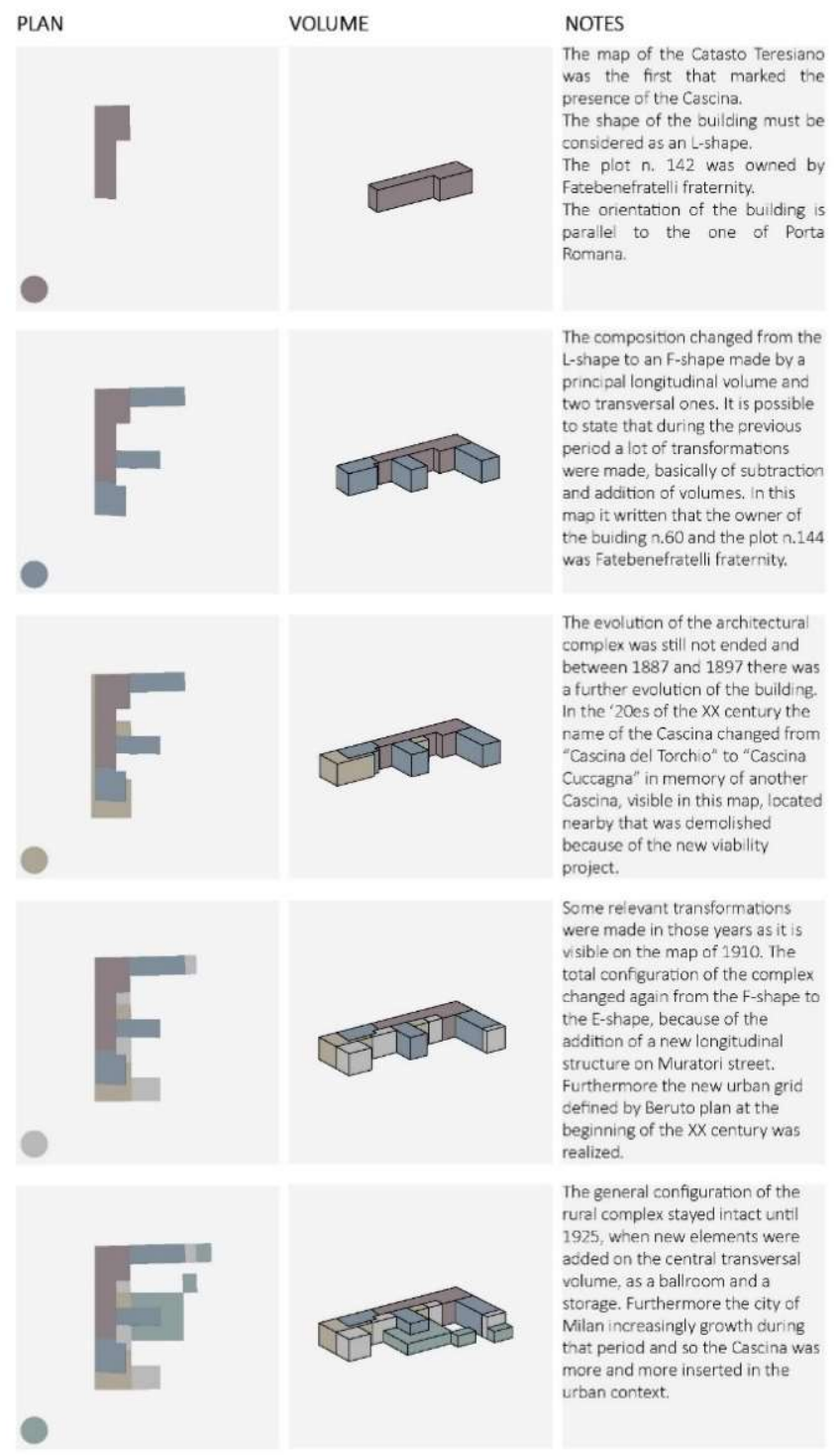

Figure 4. Historic survey of construction phases. 

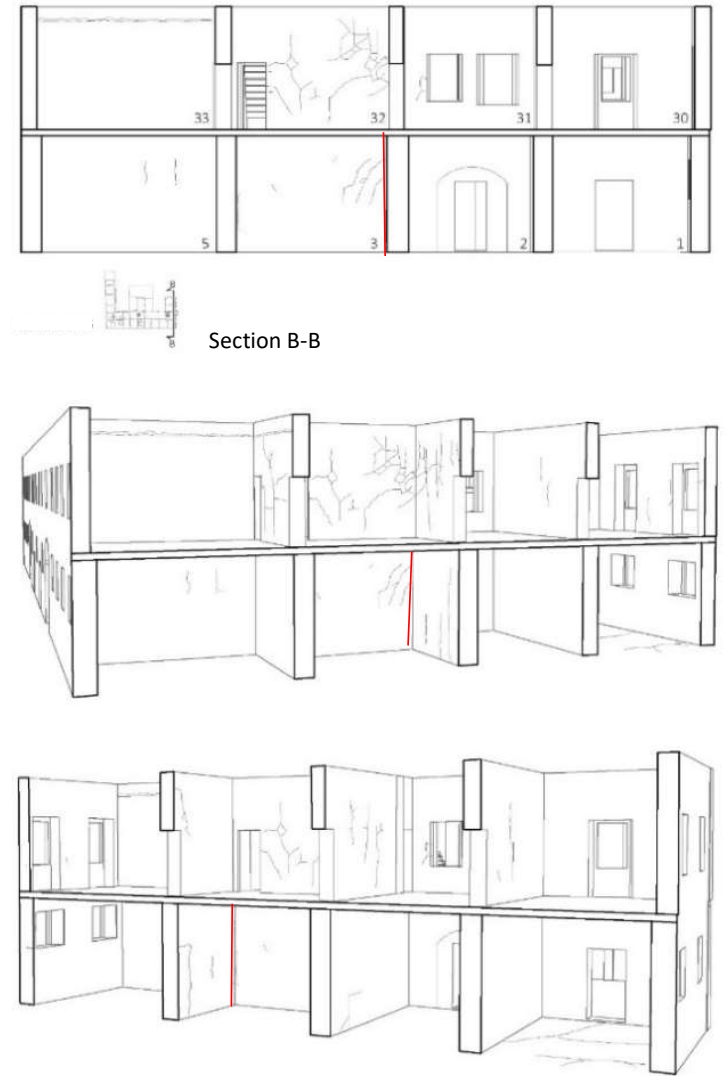

Prospective views from section B-B

Figure 5. Example of crack pattern (in red a crack probably due to lack of connection between two blocks built in different construction periods).

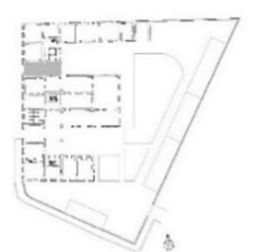

DECAY PHENOMENA INDEX

1.PULVERIZATION/SPALING

$\square$ 2.BIOLOGICAL DEPOSIT

3.STAINING
$>$ 4.SPUNTERING

3.SPUNTERING

6.WOOOD DETERIOARTION

7.VERTICAL JOINTS

8.MORTAR DETACHMENT

9.PLASTER DETACHMENT eXterna

10.PLASTER DETACHMENT intern

G11.PATINA

12. LOSS OF BON

13.SCALING

14.RUST

$\boldsymbol{\Lambda}_{15 . \text { HOLES }}$

$\square$ NON-ACCESSIBLE ROO
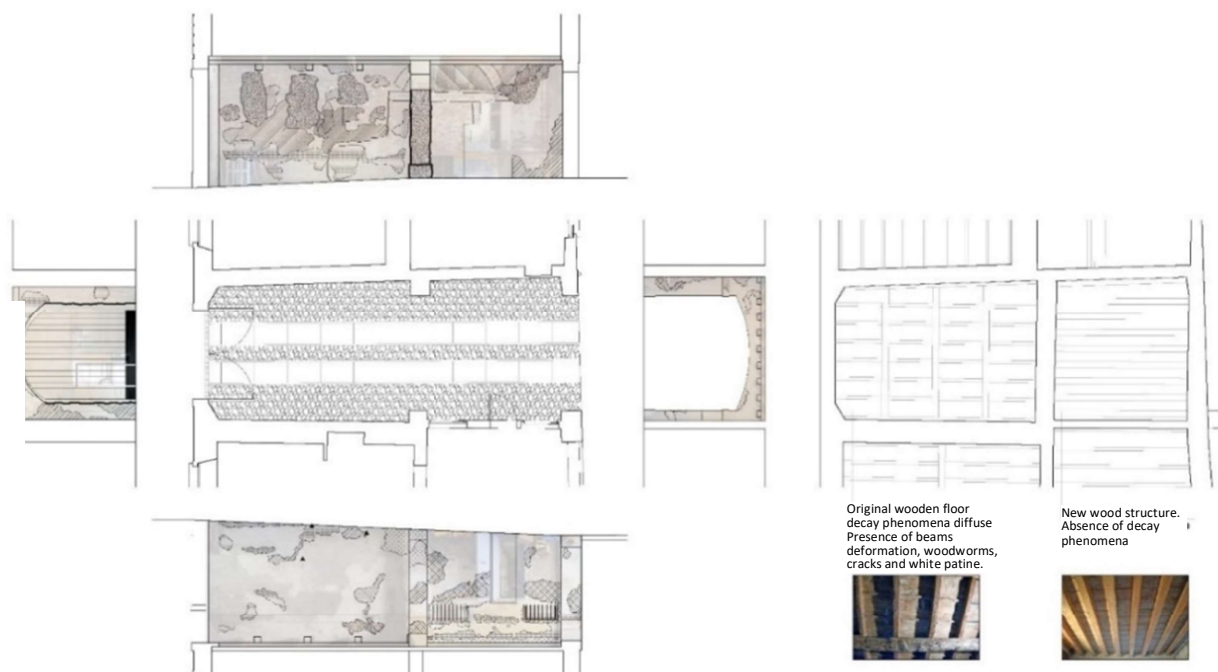

Figure 6. Crack pattern representation for each room of the building. 


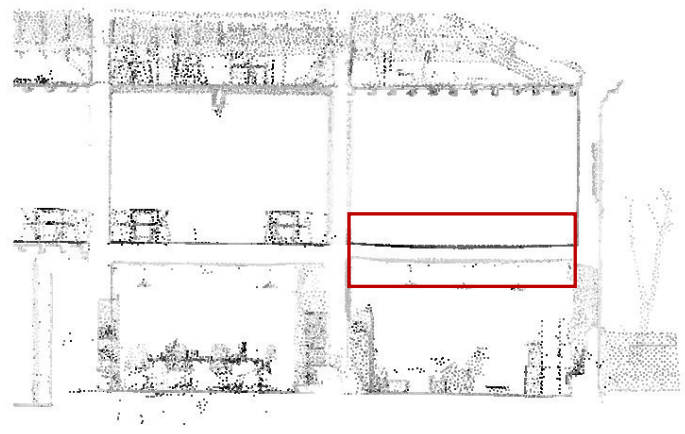

(a)

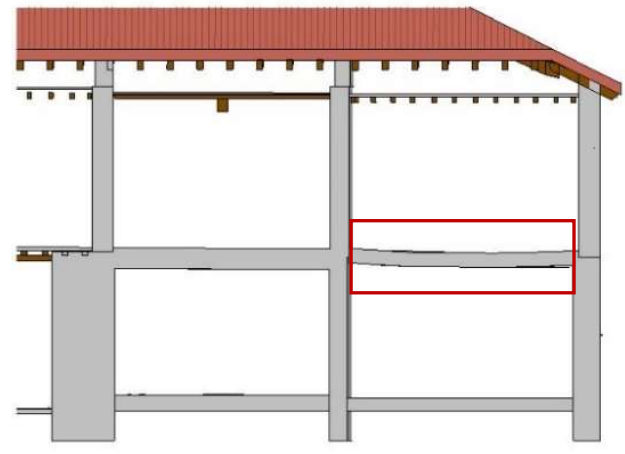

(b)

Figure 7. Example of survey of a flexural anomaly in a floor beam (a) laser scanner survey; (b) section redrawing.

The construction of the 3D model, again in a BIM environment (Figure 8), was the next step in planning the management of the whole structural system in the phase of identification of specific vulnerabilities and in the phase of design and management of seismic consolidation and adaptation interventions.

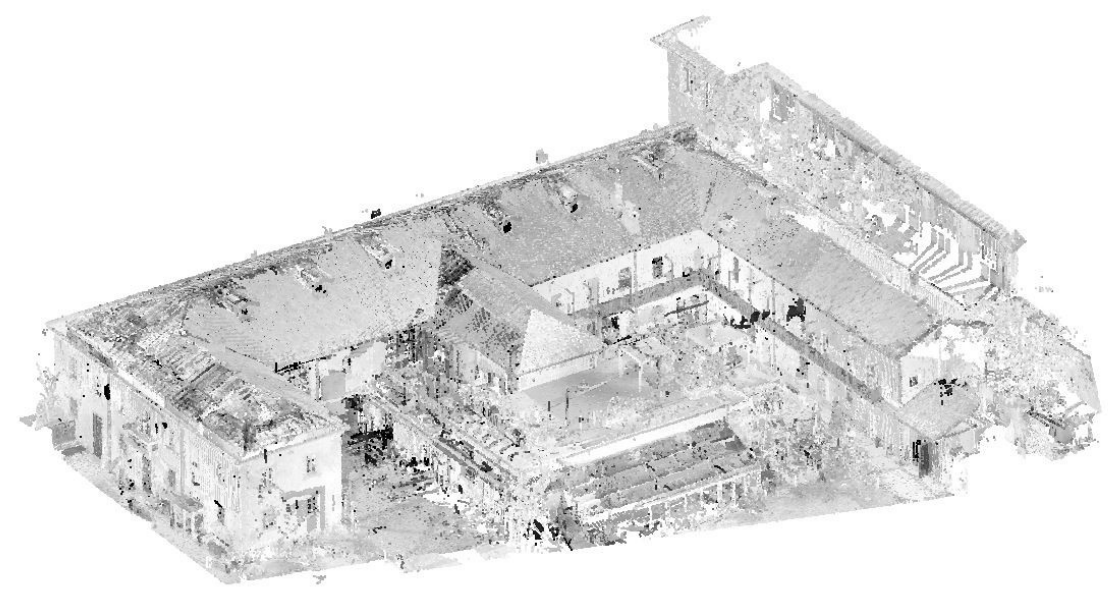

(a)

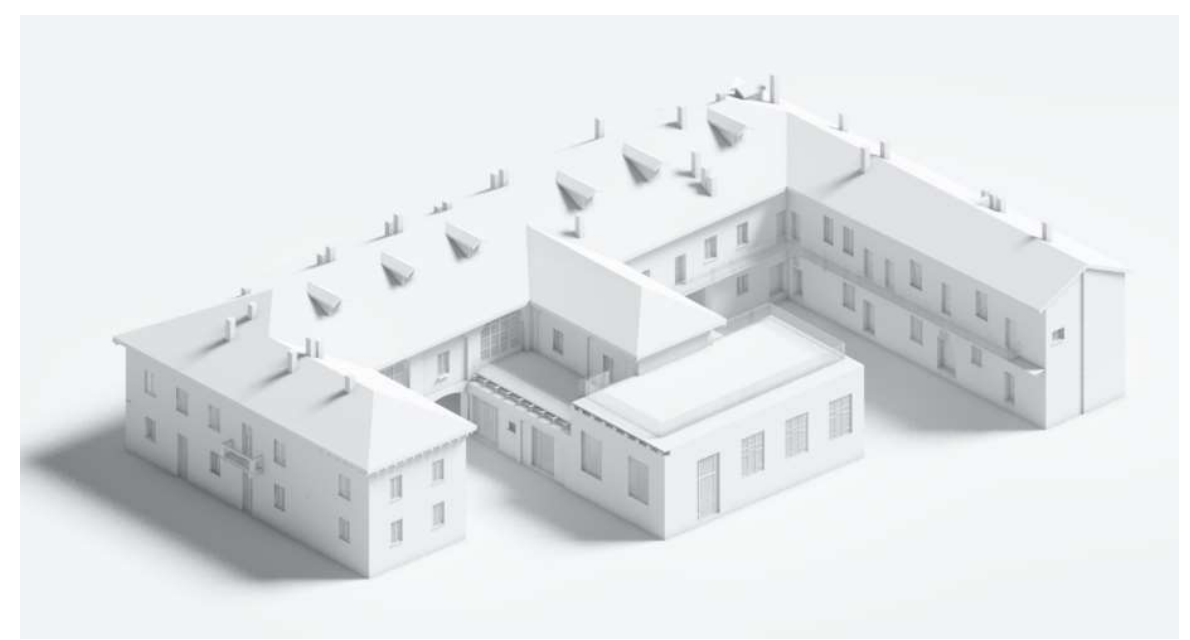

(b)

Figure 8. Reconstruction of the parametric 3D model and photorealistic representation of the white-model render: (a) point cloud, (b) re-drawing. 


\subsection{Mechanical Characterization of Materials and Rapid Vulnerability Analysis}

The survey on the masonry quality has shown masonry with variable quality, depending above all on the time of construction (Figure 4). In this case, the calculation of a safety factor SF (\%) (Equation (2)) is not required, but we can assume that: for class A masonry, SF can be considered greater than $80 \%$ of the value required by law; for class B masonry, it can be considered in the range of $50 \%-75 \%$; while for class $C$ masonry, it can be considered between $25 \%$ and $50 \%$ of the value required by law. The walls tested, except for a couple of cases, show a medium/high behavior to the transmission of vertical loads, and some criticalities for the transmission of out of plane loads on the most deteriorated panels.

The rapid vulnerability assessment showed a good overall behavior for the whole building $\left(S F_{V G}\right.$ $>80 \%$ ) and also a good behavior of the wall leaves which, in case of an earthquake, could be subject to tilting mechanisms $\left(S F_{V L}>80 \%\right)$. On the other hand, some roof and inter-storey floors showed problems in transmitting vertical loads $\left(60 \%<S F_{V S}<40 \%\right)$.

The presence of non-structural elements that could cause vulnerability, such as flue pipes or balconies and walkways, together with poor floor-masonry anchoring, led to a vulnerability level of type B2 (Table 3).

The surveys, crack pattern observation and the rapid evaluations which were carried out have indicated some important shortcomings, worthy of diagnostic investigation. Therefore, the following were carried out:

- Geo-radar surveys in some rooms of the Cascina to understand the direction of floor structural elements when covered with a thatched ceiling, to verify the wall thickness as well as the foundations depth and size. The foundations investigation has also confirmed the probable difference in the construction period of some parts of the building [27,28];

- Sonic investigations on some walls, in those areas where the crack pattern showed fissures of doubtful interpretation, in order to investigate the panel homogeneity and identify possible detachments of internal leaves and/or surface plasters;

- Superficial and deep penetrometric tests for mortars characterization;

- Bricks characterization based on the behavior detected on bricks preserved on site and probably contemporary to the ones in use. The results obtained were compared with values available in the literature for materials of the same type and period [29-31];

- Penetrometric tests (CResistograph) to characterize the timber floors and roofs [32-34].

Normally, a focused diagnostic phase such as the one described above affects less than $6 \%$ the cost of the building's safety intervention.

\subsection{Identification of Specific Vulnerabilities}

From the rapid evaluations and the experimental tests carried out, each vertical and horizontal structural element and all the non-structural elements could be classified as indicated in Table 4 . Each type of specific vulnerability found on individual elements was assigned a weight, according to the damage level obtained in the previous investigations: absent damage (0), scarcely influential (1), averagely influential (2), significantly influential (3). The result of this operation is presented in a matrix with a correspondence between structural elements and specific vulnerabilities, useful to characterize the elements in a BIM environment. In the commercial software that was used, in addition to the geometric, mechanical, and material characteristics, each structural element could be associated with the table of specific vulnerabilities and weights assigned to each item referred to that element. (Figure 9).

\subsection{Queries on Vulnerability Levels Carried Out in the BIM Environment}

Once the 3D model of the building had been prepared in a BIM environment and the matrix of the correspondence between structural elements and specific vulnerability had been constructed, the queries were carried out. 
After associating the vulnerabilities and their respective weights to the building elements, a colored field (selected by the user for each query) was connected with each weight and queries were carried out about the presence or absence of vulnerability elements and their influence on the assessment of the overall vulnerability of the building (Figure 9).

Different types of queries can be performed. The system can be queried about the presence of a certain type of specific vulnerability throughout the building and its degree of incidence on a given element or on the overall vulnerability of the system (Figure 10). The presence of two or more specific vulnerabilities with different degrees of incidence on the overall vulnerability can also be visualized (Figures 10 and 11).

An interesting aspect is the possibility to know which elements are particularly vulnerable because they are affected by two or more criticalities, each measured by its weight on the global vulnerability. By carrying out a single query, the BIM system is able to respond to the question by highlighting the elements that present all (and only) the queried criticalities and with the weights investigated. The graphic result is the coloring of the elements affected by these vulnerabilities (Figures 12 and 13).

If effective structural improvements had been made, like an improvement of the connection between the walls and the thrusting roof, the level of damage associated with the elements will be decreased; so, by making new queries, the effectiveness of the improvements and their location will be visualized in the model.

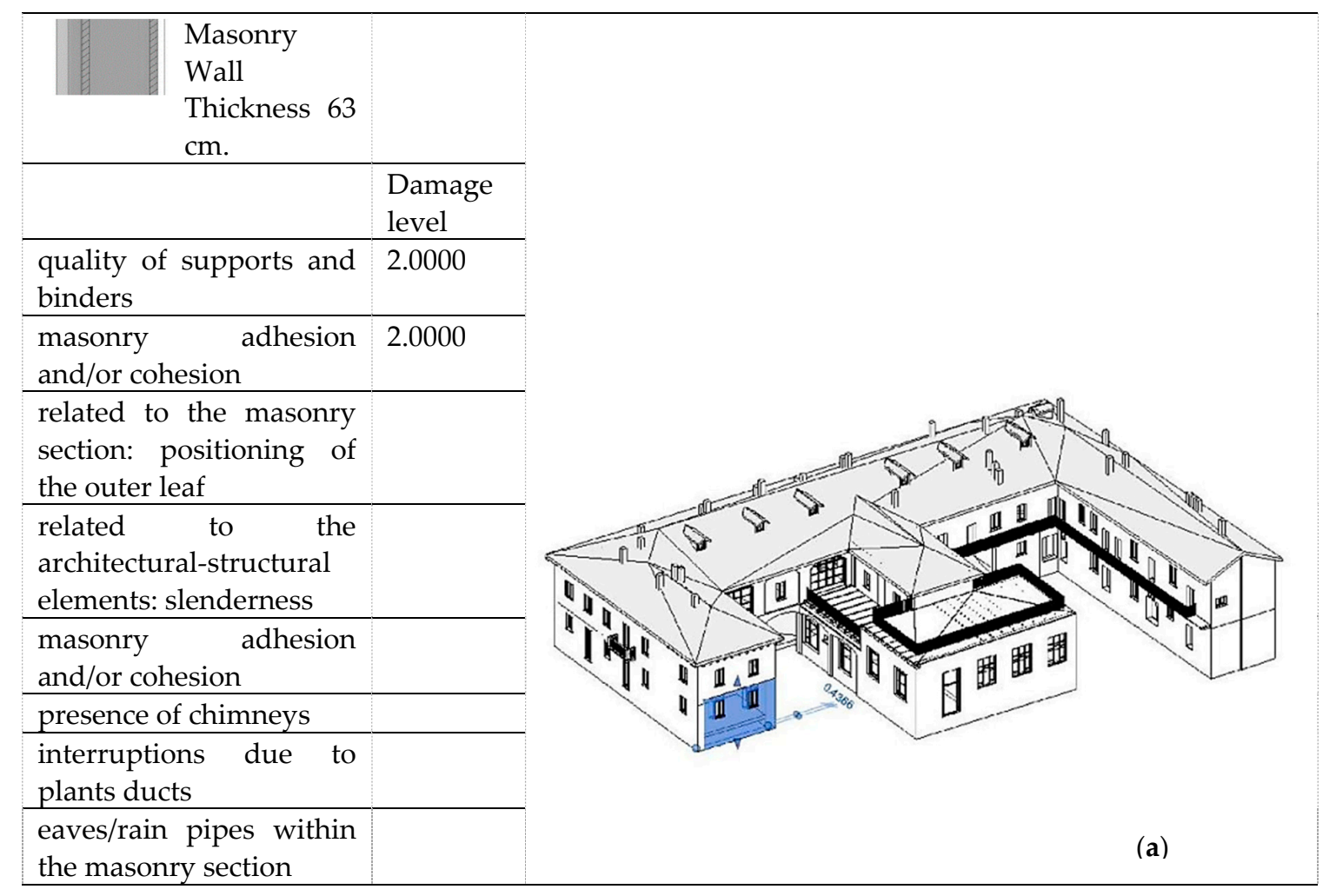

Figure 9. Cont. 


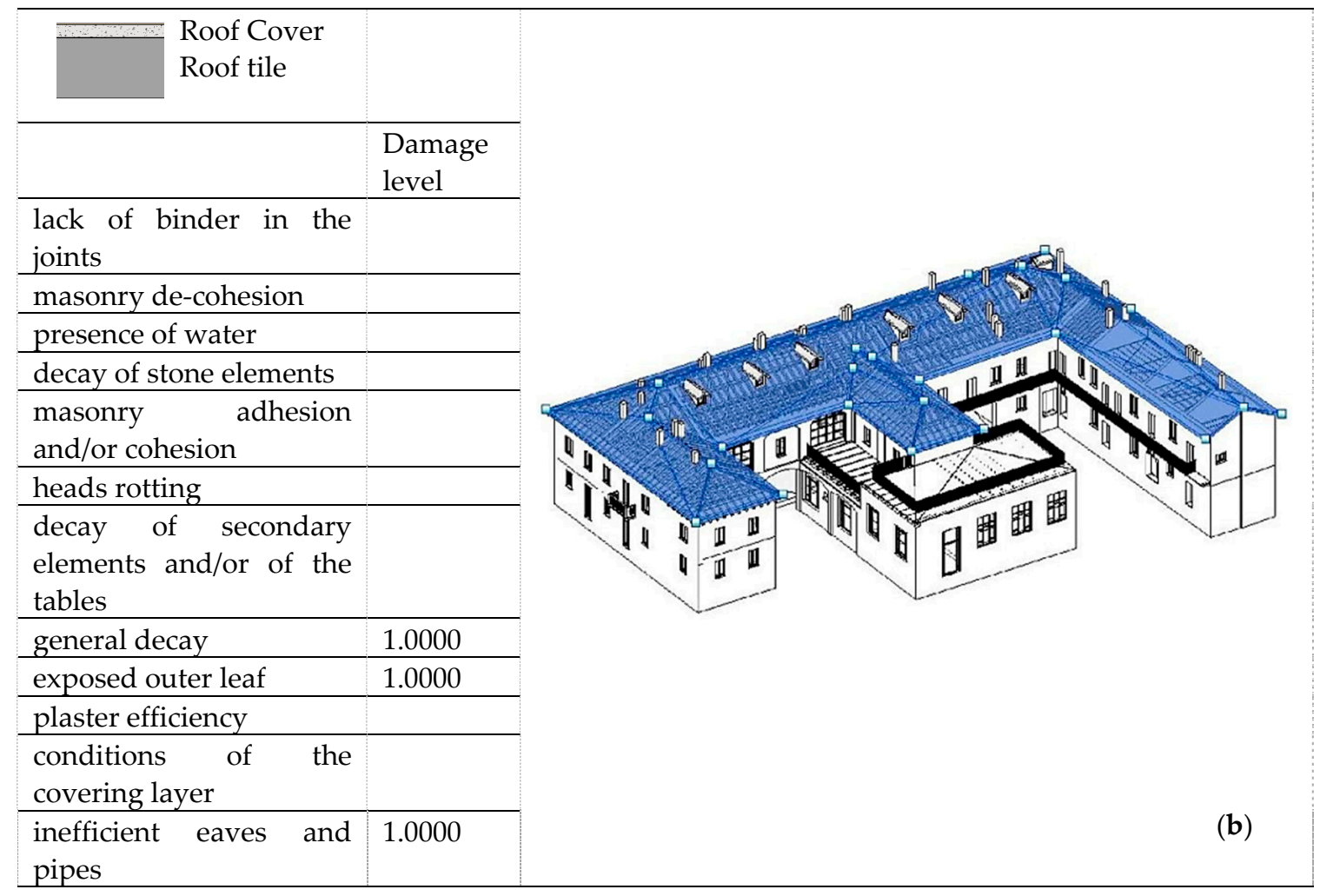

Figure 9. Example of coupling between structural element, specific vulnerability, and associated weights: (a) masonry wall thickness; (b) roof cover.

\section{CHART_01

QUERIED VULNERABILITY INDEXES

Presence of chimneys

LEGEND

$\begin{array}{ll}\text { Label } & \text { Rule } \\ \square & \text { presence of chimneys }=2 \\ \square & \text { presence of chimneys }=3\end{array}$

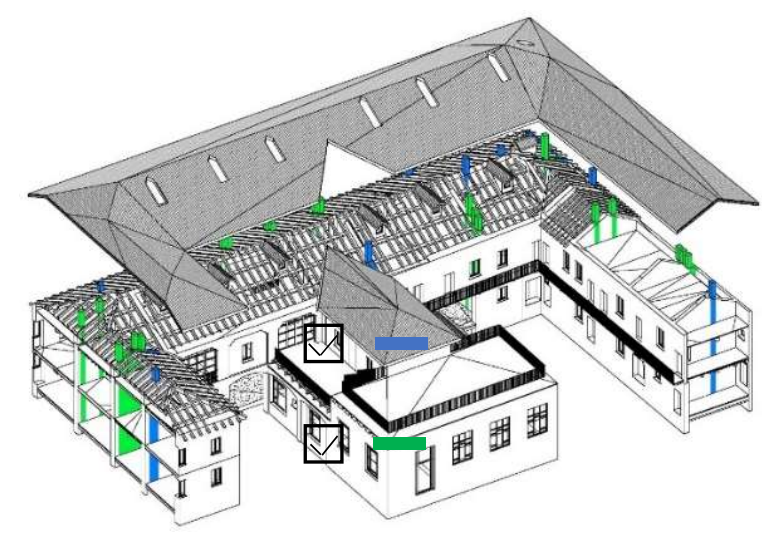

Figure 10. Simple query: presence of flue pipes and their degree of incidence on the vulnerability of the wall panel. 


\section{CHART_02 \\ QUERIED VULNERABILITY INDEXES}

Lack or poor effectiveness of connections walls-roof

Lacking or ineffective ties

Conditions of the covering layer

\section{LEGEND}

Label Rule

$\square$ lack or poor effectiveness of

connections walls-roof $=2$

$\nabla$ lacking or ineffective ties $=2$

$\square$ conditions of the covering layer $=1$

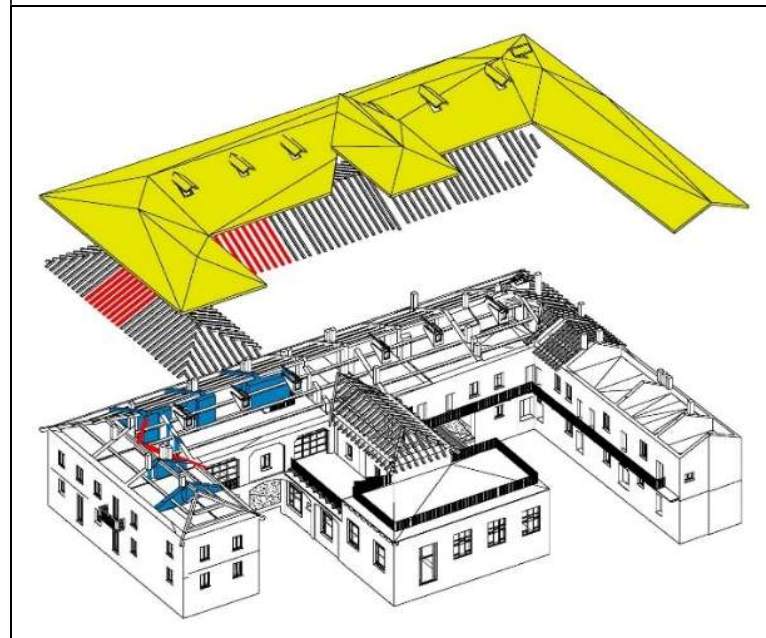

Figure 11. Integrated queries: display of three different types of specific vulnerabilities with an impact of less than 2 on the overall vulnerability. 


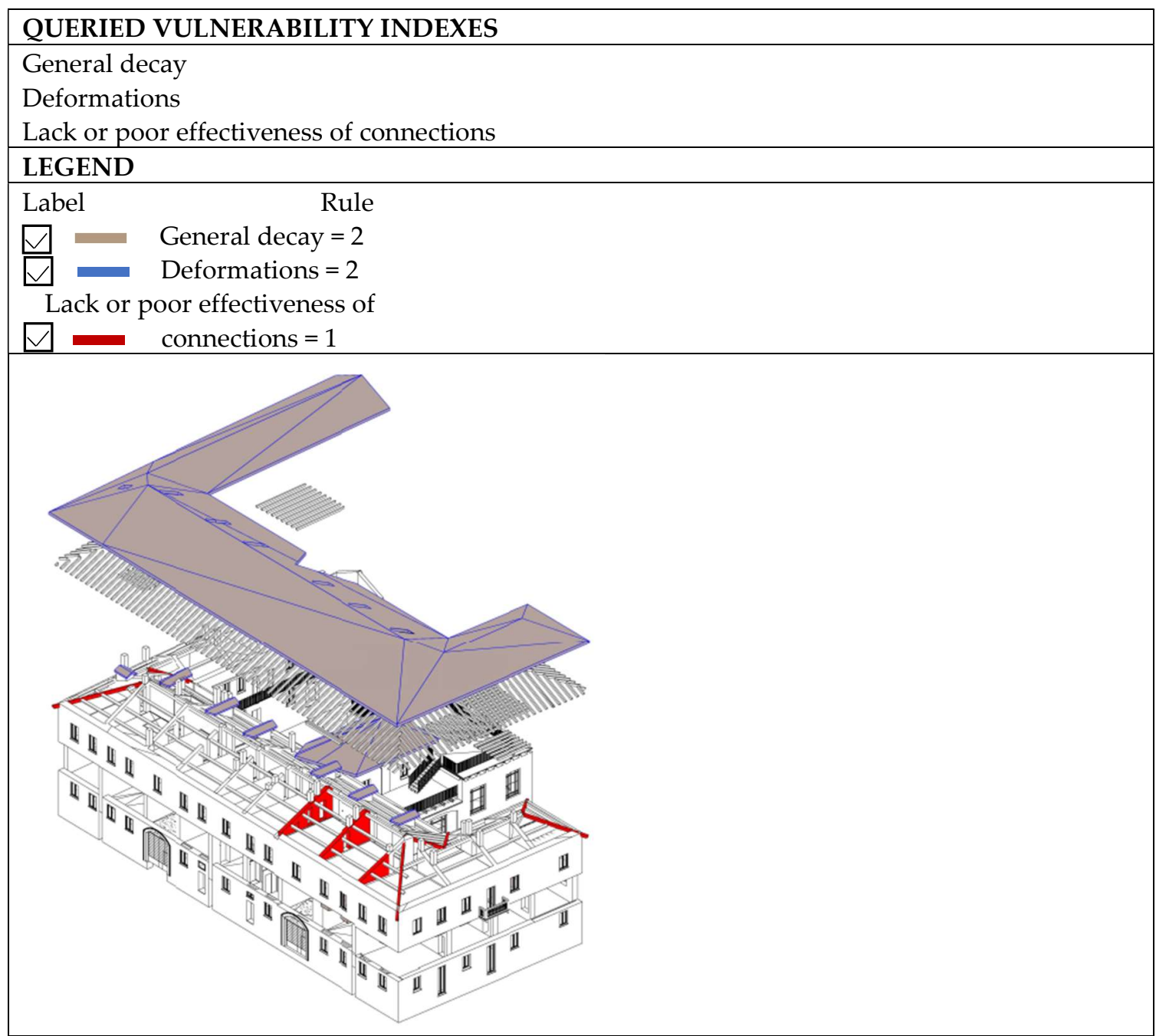

Figure 12. Multiple queries: presence of multiple vulnerabilities with different weights on the same element of the system. The coloring identifies the elements affected by all 3 vulnerabilities in the legend with their weights. 


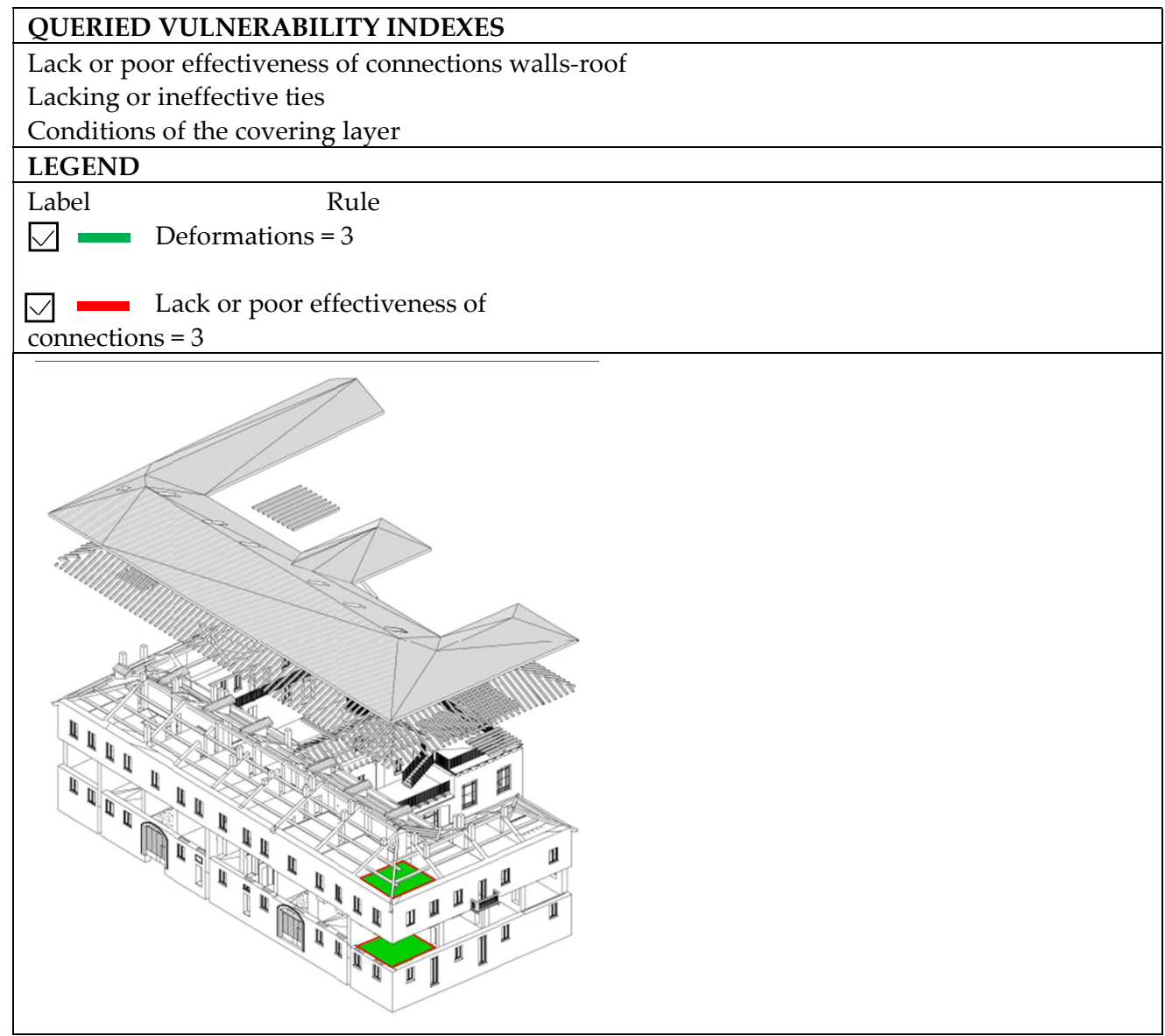

Figure 13. Multiple queries: presence of multiple vulnerabilities with different weights on the same element of the system. The coloring identifies the elements affected by all 2 vulnerabilities in the legend with their weights.

\section{Conclusions and Future Developments}

The research issue of assessing the seismic vulnerability of existing buildings is still unresolved. For about thirty years, scholars and researchers have been working on quantifying the seismic vulnerability of historical buildings, following different approaches at different levels of detail (rapid, static, dynamic approaches, etc.).

This open-ended problem is raising awareness among the public and owners of the need for implementing safety measures even on buildings not hit by the earthquake in areas with medium-low seismicity.

In this work, we presented the application of a procedure for assessing the seismic vulnerability of an existing building based on survey tools already present in the guidelines of several Italian Regions.

The procedure has proved to be effective and easy to use for a professional. The innovative part of the work carried out consisted of the graphic representation of the results obtained.

Until now, the degree of vulnerability of individual elements or macro elements was only possible in tabular or diagrammatic form, not easy to understand for non-experts. In this work, the use of design in a BIM environment has been experimented. The adopted investigation procedure and the non-destructive diagnostic tests used allowed definition of, for each structural element, a detailed classification of its vulnerabilities and their weight on the overall building vulnerability.

Therefore, in addition to the classic geometric, mechanical, and material characteristics, the use of a BIM model allowed associating to each structural element the presence of vulnerability aspects and their weight. By means of focused queries, specific vulnerabilities present in the building and the reached level of damage (measured as a weight on the total vulnerability) could be highlighted. The 
graphic representation is very helpful to understand both the location of critical points and the problem severity. The owner becomes aware that the building presents problems and that the interventions have different degrees of urgency but are necessary; on the other hand, the designer has a tool to plan, in terms of time, the maintenance and adaptation interventions and to control ex-post the effectiveness of the interventions carried out.

The procedure presented here served as a basis for planning the consolidation and safety interventions on Cascina Cuccagna in Milan. Critical issues in the floors of the South-West wing and of the South-East wing have been highlighted that require immediate static safety interventions. The floors in the corner area between the South-East and the South-West wings also turned out to be poorly connected to the perimeter masonry and require seismic adaptation. In addition, historical analysis and geo-radar survey of the foundations have shown that the South-West wing is posterior to the South-East wing; redrawing of the cracked pattern has shown a possible poor connection between the perimeter walls of the two wings. All these aspects have been reported in the BIM environment and expressed in graphic form. Thus, the designers were able to plan the most urgent interventions.

Of course, designing in a BIM environment is not without difficulties. First of all, every element of the project must be precisely defined; if this gives great advantages to managing the construction site, certainly it is a not easy constraint in the architectural design phase. In fact, if the architectural design criteria do not follow the BIM environment logic from the very beginning, then the subsequent modeling in a BIM environment is not so easy. Difficulties have also been met due to the compatibility between CAD graphics and structural modeling programs, used in professional practice, with modeling in a BIM environment; this affects the easy transfer of project files in this environment.

These problems are mitigated when the application deals with existing assets, where geometries and materials are given and the implementation in a BIM environment is easier. However, it is necessary to underline that working on existing buildings also requires modeling of structural sections often out of plan, variable, or deformed geometry not easy to shape with the simple elements present in the software. Therefore, simplifications or devices are often used to facilitate the three-dimensional construction of the building and the interchange with third-party software (structural, energy, computational, etc.). This aspect must be solved as well as the improvement of graphic resolution; the architectural side is still very poor and forces professionals to produce two or more types of design tables. Another aspect in which the current BIM modeling is poor is its software compatibility to facilitate professional use.

As for the procedure introduced here, the authors believe that the proposed procedure can be replicated with the same degree of effectiveness on other existing buildings and represents a real way of involving the client in the safety processing of the existing historical heritage. However, in order to improve the input of collected data and the graphic output, it will still require application efforts concerning both different vulnerabilities and monitoring of the effectiveness of the implemented actions for static and seismic adaptation.

Author Contributions: Conceptualization, E.G.; Methodology, E.G. and A.A.; Structural evaluation, Writing, E.G.; Restoration, Reviewing and Editing, A.A.; Methodology, Validation, F.M.; Laser scanner survey, BIM application, F.V. All authors have read and agreed to the published version of the manuscript.

Funding: The following research is funded by the CARIPLO Foundation, Milan, Italy, in the context of the 2017 Art and Culture-Cultural Heritage at Risk Calls, Project PRE.CU.R.S.OR.

Acknowledgments: Thanks to the ACCC association of Cascina Cuccagna, the design team of Hydea s.p.a. and Eng. Luciano Ardito for the collaboration undertaken in this project.

Conflicts of Interest: The authors declare no conflict of interest.

\section{References}

1. Dell'Orto, C.; Guzzetti, F.; Maroldi, F.; Molina, C. G.I.S. for the post-earthquake damage assessment. The case of the Fontecchio historic heritage. In Proceedings of the National Conference Sicurezza e Conservazione nel Recupero dei Beni Culturali Colpiti da Sisma. Strategie e Tecniche di Ricostruzione ad un Anno dal Terremoto Abruzzese, Venice, Italy, 8-9 April 2010; CD-ROM. pp. 1-10. (In Italian). 
2. Dell'Orto, C.; Maroldi, F. Post-Earthquake damage evaluation and reconstruction strategies: G.I.S. on Fontecchio. In Proceedings of the 14th National Conference ASITA, Brescia, Italy, 9-12 November 2010; CD-ROM. pp. 835-840. (In Italian).

3. Paudel, B.; Pradhan, P.K. Seismic Vulnerability Assessment of Buildings in GIS Environment: Dhankuta Municipality, Nepal. Geogr. J. Nepal 2011, 9, 1-12. [CrossRef]

4. Ricci, P.; Verderame, G.M.; Manfredi, G.; Pollino, M.; Borfecchia, F.; De Cecco, L.; Martini, S.; Pascale, C.; Ristoratore, E.; James, V. Seismic Vulnerability Assessment Using Field Survey and Remote Sensing Techniques. In Proceedings of the International Conference on Computational Science and its Application, ICCSA 2011, Santander, Spain, 20-23 June 2011; Murgante, B., Ed.; Springer: Berlin/Heidelberg, Germany, 2011. Part II, LNCS 6783. pp. 109-124. [CrossRef]

5. Ahmed, M.M.; Jahan, I.; Alam, J. Earthquake Vulnerability Assessment of Existing Buildings in Cox's-Bazar using Field Survey \& GIS. IJERT Int. J. Eng. Res. Technol. 2014, 3, 1147-1156. Available online: https://www.ijert.org/research/earthquake-vulnerability-assessment-of-existing-buildings-in-coxsbazar-using-field-survey-gis-IJERTV3IS080729.pdf (accessed on 8 July 2014).

6. Rahman, N.; Ansary, M.A.; Islam, I. GIS based mapping of vulnerability to earthquake and fire hazard in Dhaka city, Bangladesh. Int. J. Disaster Risk Reduct. 2015, 13, 291-300. [CrossRef]

7. Rezaie, F.; Panahi, M. GIS modeling of seismic vulnerability of residential fabrics considering geotechnical, structural, social and physical distance indicators in Tehran using multi-criteria decision-making techniques. Nat. Hazards Earth Syst. Sci. 2015, 15, 461-474. [CrossRef]

8. Taffarel, S.; Marson, C.; Valotto, C.; Rovevrato, M.; Munari, M.; Da Porto, F.; Modena, C. Seismic vulnerability maps of Timisoara historical centre based on fragility curves. In Proceedings of the 10th International Conference on Structural Analysis of Historical Constructions, SAHC2016, Leuven, Belgium, 13-15 September 2016; Von Balen, K., Verstrynge, E., Eds.; CRC Press: Boca Raton, FL, USA, 2016.

9. Taffarel, S.; Caliman, M.; Valluzzi, M.R.; Modena, C. Seismic vulnerability assessment of clustered historical centers: Fragility curves based on local collapse mechanisms analyses. In Proceedings of the IB2MAC, 16th International Brick and Block Masonry Conference, Trends, Innovations and Challenges, Padua, Italy, 26-30 June 2016; Modena, C., da Porto, F., Valluzzi, M.R., Eds.; CRC Press, Taylor \& Francis Group: London, UK, 2016. A Balkema Book, electronic support. pp. 2499-2506, ISBN 9781138029996. [CrossRef]

10. Sadrykia, M.; Delavar, M.R.; Zare, M. A GIS-Based Fuzzy Decision Making Model for Seismic Vulnerability Assessment in Areas with Incomplete Data. ISPRS Int. J. Geo-Inf. 2017, 6, 119. [CrossRef]

11. Taffarel, S. Metodi Speditivi Per la Valutazione Della Vulnerabilità Sismica Del Costruito Storico: Approccio All'incertezza Nelle Forme di Aggregazione Complessa a Diversa Scala. Ph.D. Thesis, dBC Department, University of Padua, Padua, Italy, 2017. (In Italian).

12. Coccia, D.E. Interoperabilità BIM-GIS Nella Classificazione Della Vulnerabilità Sismica Degli Edifici. Master's Thesis, Politecnico di Torino, I School of Engineering, Turin, Italy, 2017. (In Italian).

13. Welch, D.P.; Sullivan, T.; Filiatrault, A. Potential of Building Information Modelling for seismic risk mitigation in buildings. Bull. New Zealand Soc. Earthq. Eng. 2014, 47, 253-263. Available online: https://www.nzsee.org.nz/library/nzsee-quarterly-bulletin/vol-41-50/ (accessed on 8 July 2014). [CrossRef]

14. Christodoulou, S.E.; Vamvatsikos, D.; Georgiou, C. A BIM-Based Framework for Forecasting and Visualizing Seismic Damage, Cost and Time to Repair. In eWork and eBusiness in Architecture, Engineering and Construction; Menzel, Scherer, R., Eds.; Taylor \& Francis Group: London, UK, 2010; pp. 33-38. ISBN 978-0-415-60507-6.

15. Alirezaei, M.; Noori, M.; Tatari, O.; Mackie, K.R.; Elgamal, A. BIM-Based Damage Estimation of Buildings under Earthquake Loading Condition. Procedia Eng. 2016, 145, 1051-1058. [CrossRef]

16. Xu, Z.; Lu, X.; Zeng, X.; Xu, Y.; Li, Y. Seismic loss assessment for buildings with various -LOD BIM data. Adv. Eng. Inform. 2019, 39, 112-126. [CrossRef]

17. Borri, A.; De Maria, A.; Casaglia, S. The EAL-M method for the seismic classification of the existing masonry buildings: A comparison between different methods and preliminary evaluations of other typologies. Progett. Sismica 2014, 5, 11-29. Available online: http://dx.medra.org/10.7414/PS.5.2.11-29 (accessed on 8 July 2014). (In Italian).

18. Borri, A.; De Maria, A. Masonry Quality Index (MQI): Correlation with the mechanical characteristics and knowledge levels. Progett. Sismica 2015, 6, 45-63. (In Italian) [CrossRef]

19. Borri, A.; Corradi, M.; Castori, G.; De Maria, A. A method for the analysis and classification of historic masonry. Bull. Earthq. Eng. 2015, 13, 2647-2665. [CrossRef] 
20. Borri, A.; De Maria, A. La Classificazione Sismica: Un Protocollo Metodologico Già Operativo Applicabile Agli Edifici Esistenti in Murature, Ingegno-Web. 2016. Available online: https://www.ingenio-web.it/6003-la-classificazione-sismica-un-protocollo-metodologico-gia-operativoapplicabile-agli-edifici-esistenti-in-muratura (accessed on 8 July 2016).

21. Binda, L.; Saisi, A.; Tiraboschi, C. Investigation procedures for the diagnosis of historic masonries. J. Constr. Build. Mater. 2000, 14, 199-233. Available online: https://www.sciencedirect.com/journal/construction-andbuilding-materials/vol/14/issue/4 (accessed on 8 July 2000). [CrossRef]

22. Binda, L.; Borri, A.; Cardani, G.; Doglioni, F. Scheda Qualità Muraria: Relazione Finale e Linee Guida per la Compilazione Della Scheda di Valutazione Della Qualità Muraria; Report ReLUIS 2005-2008; DPC Department Of Civil Protection: Rome, Italy, 2009. (In Italian)

23. Erberik, M.A. Generation of fragility curves for Turkish masonry buildings considering in-plane failure modes. Earthq. Eng. Struct. Dyn. 2008, 37, 387-405. [CrossRef]

24. Rota, M.; Penna, A.; Magenes, G. A methodology for deriving analytical fragility curves for masonry buildings based on stochastic nonlinear analyses. Eng. Struct. 2010, 32, 1312-1323. [CrossRef]

25. Pagnini, L.C.; Vicente, R.; Lagomarsino, S.; Varum, H. A mechanical model for the seismic vulnerability assessment of old masonry buildings. Earthq. Struct. 2011, 2, 25-42. [CrossRef]

26. Doglioni, F. Codice di Pratica (Linee Guida) per la Progettazione Degli Interventi di Riparazione, Miglioramento Sismico e Restauro dei Beni Architettonici Danneggiati dal Terremoto Umbro-Marchigiano del 1997; BUR, 29 settembre 2000, bollettino ufficiale della regione Marche, anno XXXI • n. ed. s. 15; Regione Marche: Ancona, Italy, 2000; Available online: http://www.ahrcos.it/newsite/terremoto/Codice_di_pratica_terremoto_ umbromarchigiano97.pdf (accessed on 8 July 2000). (In Italian)

27. Binda, L.; Zanzi, L.; Lualdi, M.; Condoleo, P. The use of georadar to assess damage to a masonry Bell Tower in Cremona, Italy. NDT E Int. 2005, 38, 171-179. [CrossRef]

28. Binda, L.; Lualdi, M.; Saisi, A. Investigation strategies for the diagnosis of historic structures: On-site tests on Avio Castle, Italy, and Pišece Castle, Slovenia. Can. J. Civ. Eng. 2008, 35, 555-566. [CrossRef]

29. Candela, M.; Cattari, S.; Lagomarsino, S.; Fonti, R. Prove in situ per la caratterizzazione della muratura in pietrame grezzo alle azioni nel piano e fuori dal piano. In Proceedings of the Conference of the Italian National Association of Earthquake Engineering (ANIDIS), Padua, Italy, 30 June-4 July 2013; pp. 1-10. (In Italian).

30. Vintzileou, E. Testing Historic Masonry Elements and/or Building Models. In Perspectives on European Earthquake Engineering and Seismology; Ansal, A., Ed.; Springer International Publishing: Cham, Switzerland, 2014; Volume 1, Chapter 8. [CrossRef]

31. Marastoni, D.; Benedetti, A.; Pelà, L.; Pignagnoli, G. Torque Penetrometric Test for the in-situ characterisation of historical mortars: Fracture mechanics interpretation and experimental validation. Constr. Build. Mater. 2017, 157, 509-520. [CrossRef]

32. Ilharco, T.; Guedes, J.M.; Arêde, A.; Pauepério, E.; Costa, A.G. Analysis and diagnosis of timber structures in Porto Historical Centre. In Proceedings of the 6th International Conference on Structural Analysis of Historic Construction, Bath, UK, 2-4 July 2008; D'Ayala, D., Fodde, E., Eds.; Taylor and Francis Group: London, UK, 2008; pp. 653-661, ISBN 978-0-415-46872-5.

33. Piazza, M.P.; Riggio, M.R.; Brentari, G.B. Strengthening and control methods for old timber trusses: The queen-post truss of the Trento theatre. In Proceedings of the 4th International Conference on Structural Analysis of Historic Construction, Padua, Italy, 10-13 November 2004; Modena, C., Lourenço, P., Roca, P., Eds.; Taylor and Francis Group: London, UK, 2005; pp. 957-965.

34. Kloiber, M.; Tippner, J.; Praus, L.; Hrivinák, J. Experimental Verification of a New Tool for Wood Mechanical resistance measurement. Wood Res. 2012, 57, 383-398. Available online: http://www.woodresearch.sk/wr/ 201203/05.pdf (accessed on 8 July 2012).

(C) 2020 by the authors. Licensee MDPI, Basel, Switzerland. This article is an open access article distributed under the terms and conditions of the Creative Commons Attribution (CC BY) license (http://creativecommons.org/licenses/by/4.0/). 